\title{
A Rare Case of Buried Sharp Foreign Body (Metal Pin) Partly in Gastric Wall and Partly Outside in Gallbladder Fossa-Endoscopic Submucosal Incision and Fluoroscopy Guided Removal
}

\author{
Pankaj Desai ${ }^{1} \quad$ Mayank Kabrawala ${ }^{1} \quad$ Subhash Nandwani ${ }^{1} \quad$ Rajiv Mehta $^{1} \quad$ Chintan Patel $^{1}$ \\ Parika Kalra ${ }^{1}$ Ritesh Prajapati ${ }^{1} \quad$ Nisharg Patel $^{1}$
}

1Department of Endoscopy and EUS, Surat Institute of Digestive Sciences, Surat, Gujarat, India

J Digest Endosc 2020;10:246-247

\section{Case}

A 27-year-old male, presented with right upper abdominal pain, nausea and one episode of nonbilious vomiting. He had a history of accidental ingestion of sharp metal pin 15 days back. Patient was admitted at outside hospital for 15 days and was advised close clinical observation and conservative medical management. Multiple serial X-rays over the course of hospital stay revealed persistent position of foreign body in stomach (-Fig. 1). Patient was discharged on supportive medical treatment. His symptoms persisted and hence he was then referred to our institute.

A contrast-enhanced computed tomography (CECT) abdomen was done which revealed "a foreign body in the pyloric region of the stomach with its distal end extending into gall bladder fossa with very minimal adjacent free fluid and few small adjacent air foci (perforation; - Fig. 2).

\section{Endoscopic Findings and Technique of removal}

An upper (gastrointestinal) GI endoscopy done revealed that the foreign body had pierced the gastric wall and was imbedded deep in the wall. There was a bump seen in the region of the antrum (-Fig. 3 ) but the tip of the foreign body was not visible. So we first marked the area using a dual knife to identify the location. The area was injected with saline and methylene blue mixture and ESD was performed to dissect
Address for correspondence Dr Pankaj N. Desai, MS, FASGE, FAIGE, Surat Institute Of Digestive Sciences, Department Of Endoscopy and EUS, Vijaynagar Gate Number 3, Majura Gate Road, Surat, 395002 Gujarat, India (e-mail: drp_desai@hotmail.com).

out the submucosa and expose the muscle layer to identify the tip of the foreign body. After deep dissection, the tip was still not visible. To avoid full thickness opening of the gastric muscle layer, we tried to see if the tip was visible under fluoroscopic guidance. The tip was identified deep in the muscle and we attempted to catch the tip under fluoroscopy with

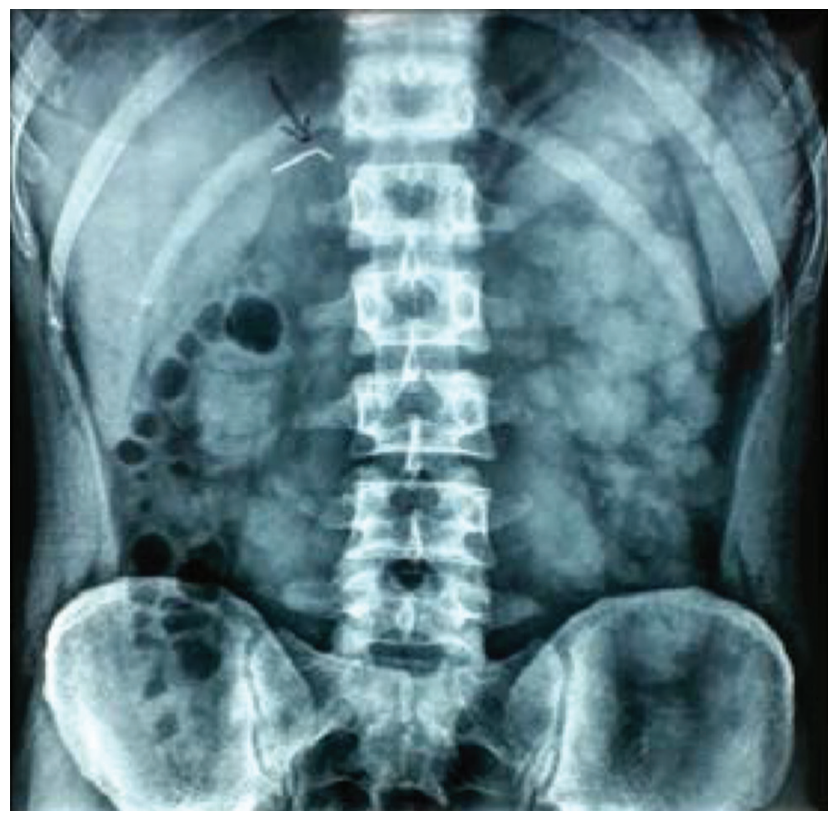

Fig. 1 X-ray abdomen showing foreign body in stomach. ISSN 0976-5042.
License terms

() (1) $\ominus \circledast$ 

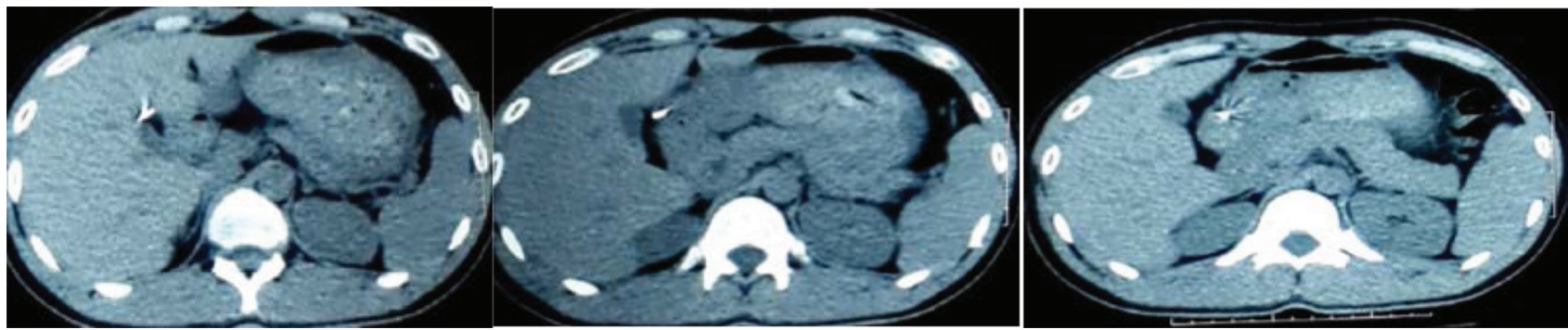

Fig. 2 CECT abdomen revealed "a foreign body in the pyloric region of the stomach with its distal end extending into gall bladder fossa with minimal adjacent free fluid and air foci (perforation). CECT, contrast-enhanced computed tomography.

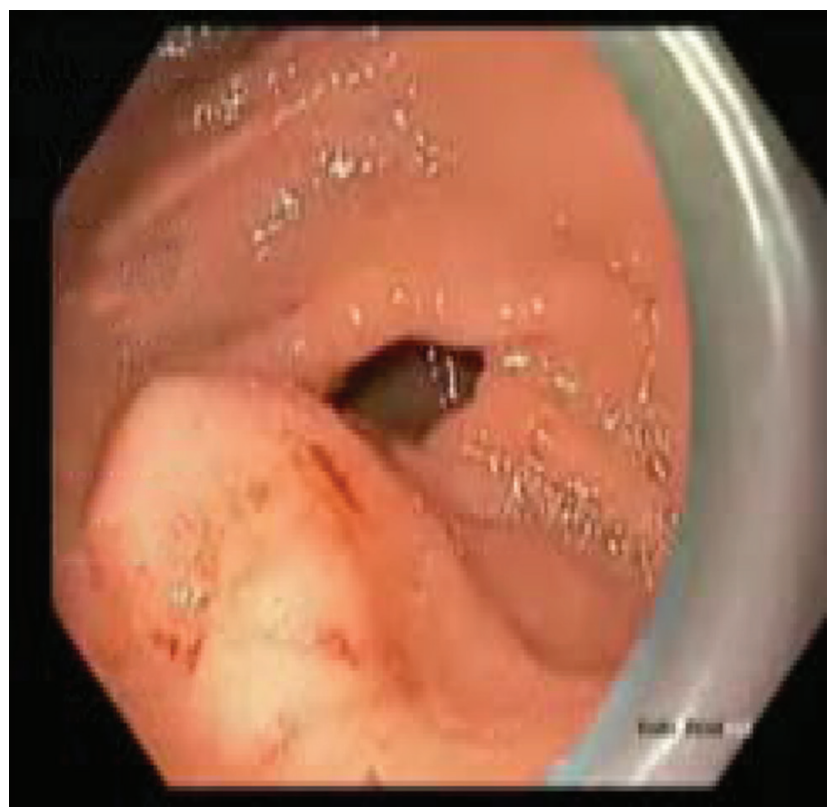

Fig. 3 Bump seen in the region of the antrum.

a rat tooth forceps ( - Fig. 4). This was difficult, as we were trying it under two-dimensional imaging. But we were successful and gently retracted the FB in a straight path, pulling it with the scope without any sideward movement to avoid injuring any adjacent organ. The tip was then gently withdrawn just a little in the biopsy channel of the scope and the entire scope removed with the FB ( - Fig. 5). Fluoroscopy confirmed no free $\mathrm{CO}_{2}$ leak from the area. A small defect in the muscle was clipped and hemostasis from the ESD site was secured using a gold probe ( - Video 1 ).

On follow-up, the patient did well. He was resumed on liquids after 6 hours and soft diet initiated after 24 hours. No complications were noted and he was discharged after 48 hours.

\section{Take Home Message}

Sharp foreign bodies are notorious in the sense that they migrate distantly and may require surgical removal with associated morbidity. Endoscopic techniques combined with fluoroscopy can salvage the situation and help to avoid surgery. The technique shows the importance of using resources at hand to remove difficult foreign bodies in the GI tract.

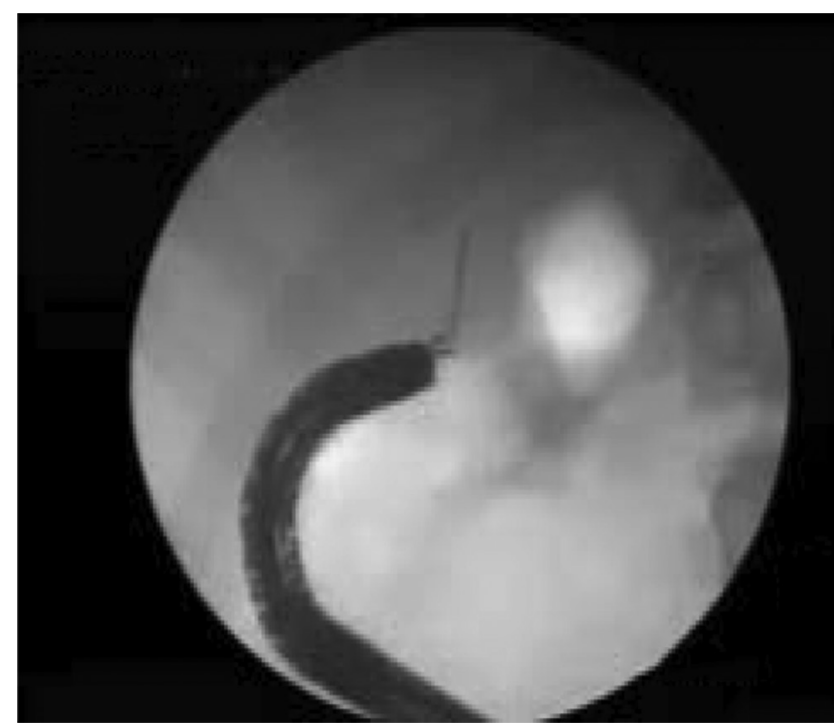

Fig. 4 Holding the tip of foreign body under fluoroscopy with a rat tooth forceps.

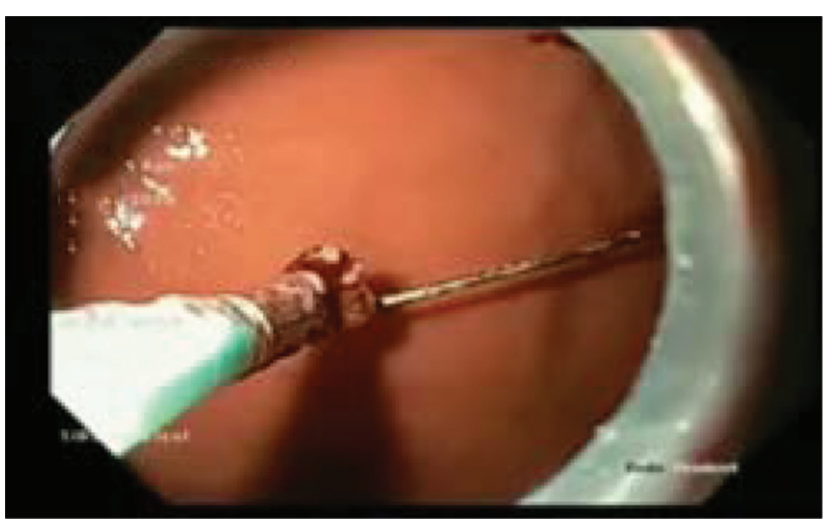

Fig. 5 Removal of foreign body.

\section{Video 1}

Foreign body extraction using ESD and fluoroscopy. Online content including video sequences viewable at: https://www.thieme-connect.com/products/ejournals/ html/10.1055/s-0040-1710157.

\section{Conflict of Interest}

None declared. 